\title{
Las mascotas corporativas de los videojuegos de los años 90: un símbolo de los millennials*
}

\author{
Pedro Vázquez-Miraz ${ }^{* *}$ \\ Recibido: 2017-11-05. Enviado a pares: 2017-12 10. \\ Aprobado por pares: 2018-01-10. Aceptado: 2018-01-28 \\ https://doi.org/10.22395/angr.v17n33a9
}

\begin{abstract}
Resumen
Se presenta en este artículo un estudio cualitativo que recopila las principales y más populares mascotas corporativas del sector de los videojuegos de la década de los años 90, una efímera tendencia empresarial que desaparecería en el siglo XXI y que estaba basada en el éxito previo de las compañías Nintendo y Sega con sus respectivas creaciones: Mario y Sonic.

Por medio de un análisis comparativo entre estos personajes de videojuegos y las características de la juventud de finales del milenio (la denominada generación Y o millennial), se ha observado que el patrón común de todos estos símbolos mercantiles se fundamentaba en representaciones sociales y culturales relacionadas con el comportamiento, el aspecto físico, las aficiones y la psique de la juventud de finales del siglo XX.

Palabras clave: videojuegos, publicidad, diseño, personaje, jugadores, adolescentes, generación Y, millennials.
\end{abstract}

Artículo inédito soportado por el proyecto Estudios de género: economía, comunicación y educación (2018) realizado bajo el amparo del grupo de investigación de Desarrollo, Salud y Desempeño Humano de la Universidad Tecnológica de Bolívar.

* Doctor en Ciencias Sociales y del Comportamiento por la Universidad de La Coruña (España) y licenciado en Psicología Social por la Universidad de Santiago de Compostela (España). Actualmente es profesor de tiempo completo de la Universidad Tecnológica de Bolívar (Cartagena de Indias, Colombia).pvasquez@utb.edu.co Orcid: http://orcid. org/0000-0002-5801-1728 


\title{
The corporate mascots of video games of the $90 \mathrm{~s}$ : a symbol of millennials
}

\begin{abstract}
This paper presents a qualitative study that compiles the main and most popular corporate mascots of the video game sector in the 90s, an ephemeral business trend that would disappear in the 21 st century and was based on the previous success of the Nintendo and Sega companies with their creations: Mario and Sonic.

Through a comparative analysis between these video game characters and the characteristics of the youth of the end of the millennium (the so-called generation Y or millennial ), it has been found that the common pattern of all these mercantile symbols was based on social and cultural representations related to behavior, physical aspect, hobbies and psyche of the youth of the late twentieth century.
\end{abstract}

Keywords: videogames, advertising, design, character, players, teenagers, Y generation, millennials.

\section{Os mascotes corporativos dos videogames dos anos 90: um símbolo dos millennials}

\begin{abstract}
Resumo
Apresenta-se neste artigo um estudo qualitativo que recopila os principais e mais populares mascotes corporativos do setor de videogames da década dos anos 90, uma efêmera tendência empresarial que desapareceria no século XXI e que estava baseada no sucesso prévio das companhias Nintendo e Sega com suas respectivas criações: Mario e Sonic.

Por meio de uma análise comparativa entre essas personagens de videogames e as características da juventude do final do milênio (a denominada geração Y ou millennial), observou-se que o padrão comum de todos esses símbolos mercantis se fundamentava em representações sociais e culturais relacionadas com o comportamento, o aspecto físico, os hobbies e a psique da juventude do final do século XX.

Palavras-chave: videogames, publicidade, design, personagem, jogadores, adolescentes, geração Y, millennials.
\end{abstract}




\section{Introducción}

El videojuego, definido como "juego electrónico en el que una o más personas interactúan (...) por medio de una pantalla (...), el cual ha ido evolucionando gracias al avance de las tecnologías, alcanzando mayor complejidad y robustez" (Rivera y Torres, p. 3), es un objeto de estudio científico, basado en los conceptos de juego, pantalla e historia (Esposito, 2005), en el que se manejan diversos paradigmas y líneas de investigación, las cuales abordan el análisis de estos productos desde diferentes enfoques, tales como los análisis descriptivos, los trabajos culturales, la ludología, los estudios narratológicos, la teoría del diseño de juegos y la semiótica (Pereira y Alonzo, 2017).

Aunque en sus inicios el videojuego fue considerado como un simple producto informático de entretenimiento infantil y juvenil, la industria que lo sostiene se ha convertido en uno de los sectores del entretenimiento más importantes del planeta, superando a otras actividades como el ámbito audiovisual (Benito-García, 2012), pudiéndose definir la industria del videojuego de la siguiente forma:

Productora de mercancías para un público masivo y global, donde uno de sus principales sustentos es el desarrollo e inversión en recursos de alta tecnología, y por otro, la creación de bienes simbólicos para el consumo, valoración y reproducción social. (Garfias, 2010, p. 162).

Como señala Vargas (2014, p. 23), desde finales del siglo pasado las compañías de videojuegos empezaron a practicar el product placement "a través de la exhibición de marcas de diversos tipos en las pantallas de los usuarios, de ordinario con marcas ligadas con el tipo de juego, temática y audiencia". El enorme número de personajes y mascotas corporativas que representaban y humanizaban a diferentes compañías del sector de los videojuegos del siglo XX, ha intentado, por lo tanto, encarnar los intereses de los jóvenes que vivieron el cambio de milenio.

Por medio del presente escrito se plantea una revisión comparativa de las mascotas corporativas más famosas de esta específica industria de ocio de los años 90, entendidas estas encarnaciones animadas como las características prototípicas de una generación entera.

La popularidad de estas representaciones ha sido un claro antecedente histórico que permite explicar la vigente importancia de los videojuegos en la sociedad actual, tanto a nivel económico como desde una perspectiva cultural.

Es, por lo tanto, relevante identificar las características físicas y psicológicas de estas creaciones artísticas y de marketing (que fueron iconos de una generación entera) llevando a cabo, para lograr tal meta, un análisis comparado entre los millennials y las célebres figuras de videojuegos de esta época histórica.

Desde el inicio-descubrimiento del fenómeno de lo juvenil y su nicho de mercado en los años posteriores a la Segunda Guerra Mundial, los cambios sociales producidos en el siglo XX ocasionaron que los jóvenes tuvieran una fuerte consciencia generacional al hacerse extrema la brecha con las generaciones pasadas (Rosario, 2001). 
Si bien el límite actual entre las distintas generaciones es cada vez más difuso, se podría afirmar que la denominada generación Y o millennial es aquella cohorte que está integrada por todos los nacidos entre los años 80 y hasta mediados de los 90 (Rochford, 2016, p. 26) o el año 2000 (Cataldi y Dominighini, 2015; Ruiz-Cartagena, 2017), así, estas personas serían las que, como jóvenes, han vivido el cambio de milenio.

Esta generación es la primera formada por nativos digitales y es el eslabón que conecta a la sociedad pretecnológica y a la actual etapa tecnológica hiperconectada basada en las redes sociales. Años que coinciden con el auge de los primeros personajes-íconos globales de los videojuegos y la decadencia de este tipo de elementos culturales.

Los millennials, las personas que más usan internet y servicios de mensajería instantánea, debido en parte a poseer un mayor nivel económico que las generaciones posteriores (Ramos y Ortega-Mohedano, 2017, pp. 706-707), fueron en su juventud los individuos que tuvieron las primeras videoconsolas populares de los años 80, de esta forma, los personajes de videojuegos también pueden explicar esta evolución generacional. Los sujetos nacidos en este período pasaron de Mario (símbolo de Nintendo y representante del hombre de a pie o del obrero) a Sonic (representación de Sega y la modernidad).

Ahora bien, irónicamente, en la actualidad, han sobrevivido en el ideario colectivo únicamente las figuras más populares e icónicas alejadas de la fisionomía tan típica de finales del siglo XX, es decir, las mascotas creadas en los años 80 (Mario, Pac-Man' de Namco o Megaman de Capcom) y alguna excepción de los años 90 (como Sonic).

\section{Antecedentes históricos: el boom de Mario}

El personaje de Mario, el célebre plomero italiano de Nintendo, fue creado a inicios de los años 80 por Shigeru Miyamoto como protagonista de un juego de arcade tradicional de la primera época de los videojuegos (Esposito, 2005): Donkey Kong, su nombre es un homenaje a Mario Segali ${ }^{2}$ (responsable de las oficinas centrales de Nintendo of America en esa década) debido a su parecido físico con el personaje (Garfias, 2010; Nintendo, s.f.).

El éxito indiscutible de Mario como imagen corporativa de esta empresa de video juegos nipona, provocó que las empresas competidoras del sector buscaran con afán su propia mascota corporativa para lograr una publicidad más efectiva. Un proceso que supuestamente permitiría obtener mayores beneficios económicos a las empresas, pues tras el éxito de Pac-Man y la revolución de Mario, "el personaje en los videojuegos recibiría el trato de celebridad y se convertía en una propiedad intelectual de gran valor" (Garfias, 2010, p. 168).

Pac-Man, es considerado el primer personaje de videojuegos: creado en 1980 por Toru Iwatana, tuvo un enorme éxito de ventas y de popularidad (Garfias, 2010, p. 168), si bien a diferencia de Mario (presentado en 1981), pasó por períodos de completa decadencia (en los años 90).

2 Los protagonistas de Donkey Kong (1980) estaban inspirados en la serie animada de Popeye el marino, el videojuego tuvo que ser modificado cuando Nintendo perdió la licencia de uso de estos personajes, así, se sustituyó al popular amante de las espinacas por un hombrecillo anónimo, el cual fue denominado inicialmente como Jumpman. 
Mario tuvo una enorme aceptación por parte del público y esta figura dio un rápido salto a los juegos para videoconsolas de sobremesa. Super Mario (1985) fue un punto de inflexión, pues este videojuego, a diferencia de los anteriores, ya tenía una historia argumental y un final claro y era completamente secundario el logro por alcanzar un mayor número de puntos; elemento tan característico de juegos de otras empresas, como los productos de la compañía japonesa Atari (Lafrance, 2003).

Con la aparición de las videoconsolas de sobremesa, los negocios de las máquinas recreativas empezaron a decaer paulatinamente, y si bien la crisis del 1983 afectó gravemente al sector, debido entre otros factores a la enorme competencia que había en el mercado de las videoconsolas y la masiva aparición de videojuegos mediocres, Nintendo y su consola NES (acrónimo de Nintendo Entertainment System), permitió a la industria de las videoconsolas superar este período crítico y que la sociedad entendiera a los videojuegos como un negocio rentable y con un prometedor futuro debido en parte a "la calidad del movimiento, el color y el sonido, la imaginación de los creadores de juegos y el considerable abaratamiento relativo de los mismos a comienzos de los 90" (Pérez-García, 2014, p. 137). Nintendo tomaba así el relevo definitivo de Atari, la compañía dominante de los videojuegos en la década anterior³ , la cual quebró en 1983 (Vázquez-Miraz, 2016).

Durante la segunda mitad de la década de los 80 , Nintendo fue la compañía dominante del sector, gracias, en parte, a los acuerdos de exclusividad que la empresa exigía a los desarrolladores de los productos y a ejercer un control máximo de los videojuegos que se vendían para su videoconsola, actos que anteriormente eran inexistentes. Mario representaba el poder omnímodo que tenía esta compañía, pues en 1988, Nintendo ya dominaba el 80\% del mercado de videoconsolas y Sega, su más cercano competidor, se tenía que conformar con una lejana cuota del 15\% (Lafrance, 2003).

La importancia de diseñar el personaje principal de un videojuego no es algo baladí, pues según Rogers (1990 citado en De Diego, 2013):

Generalmente en su estética, conducta y estilo general es la encarnación de un concepto. Valores, pensamientos o emociones son cuestiones que fácilmente pueden tomar la forma tangible de un personaje o, en historias corales más complejas, puede tratarse de un grupo de personajes que reflejan diferentes virtudes que interactúan entre ellas de forma complementaria o competitiva.

El primer juego de Mario para la NES, considerado el primer juego de plataformas de desplazamiento horizontal (Del Olmo, 2013), fue otro triunfo rotundo, que ha permitido que este personaje haya vendido más de 100 millones de unidades, siendo una figura más popular entre los menores de edad que el mismísimo ratón Mickey de la compañía Disney (Squire y Steinkuehler, 2005).

Atari fue la primera empresa que lanzó al mercado el primer sistema de videojuegos en cartucho (1977), productos que alcanzaron un gran éxito comercial y al mismo tiempo, una primera preocupación sobre los posibles efectos de los videojuegos en la conducta infantil (Pérez-García, 2014, p. 137). 
Vista la celebridad de Mario, las demás empresas del sector siguieron la estela de Nintendo a la hora de crear sus mascotas corporativas con mejor o peor fortuna. Es destacable la aparición, en 1991, del videojuego Sonic el erizo, producto protagonizado por la nueva mascota corporativa de Sega y la principal respuesta a Mario (Pettus, 2013), personaje que tuvo una gran popularidad y mantuvo una fuerte rivalidad entre las compañías Nintendo y Sega por el control del mercado de los videojuegos en los años 90. Una competencia que se vería reflejada también en los videojuegos de plataformas protagonizados por Mario y Sonic (Belli y López, 2008), llegando a ser tal la fama de estos personajes que incluso colonizaron medios de comunicación de masas más tradicionales como por ejemplo la televisión y el cine ${ }^{4}$.

Como comenta Mangirón (2012, p. 28), "la cultura popular japonesa se ha convertido en un fenómeno global, principalmente el manga, el anime y los videojuegos japoneses, que gozan actualmente de gran popularidad a nivel mundial entre los jóvenes y los no tan jóvenes" de tal forma que Mario y Sonic, se han convertido en auténticos iconos de la cultura popular global (Mangirón, 2012, p. 30).

\section{Metodología}

Como se expuso en la introducción, este estudio tiene por objeto observar las características comunes (género, aspectos físicos, rasgos psicológicos, vestimenta y meta vital) de las principales mascotas corporativas del sector de los videojuegos de finales de los años 90 pues la hipótesis de partida de este trabajo es que la creación de Sonic ha sido un patrón común para el resto de empresas de videojuegos de este período.

Por medio de una revisión exploratoria, se ha realizado un análisis comparado de las mascotas corporativas de las empresas de videojuegos de hardware y software más importantes de la última década del siglo XX (Sega, Sony, Ubisoft, Sunsoft, Accolade, Crystal Dynamics y Titus Interactive) para, posteriormente, contrastar estos componentes culturales de carácter tecnológico con las características generales de los millennials —las primeras personas que llegaron a la mayoría de edad en plena era digital (Feixa, 2006)—: personas activas y tecnológicas con una fuerte tendencia consumista que buscan la gratificación inmediata, el éxito rápido y que tienen una marcada confianza en sí mismos (Cataldi y Dominighini, 2015), sujetos que presentan, entonces, un perfil individualista, sofisticado, moderno, atrevido y rebelde (Ruiz-Cartagena, 2017).

\section{Las mascotas corporativas de las empresas de videojuegos de los años 90}

Se podría definir el concepto de mascota corporativa como la idea de un personaje que representa una amplia gama de seres humanos, animados o ficticios que es usado para promover un producto, servicio o idea (Kraak y Story, 2014), la mayoría de empresas rivales de Nintendo se caracterizan por presentar a animales antropomórficos completamente

Véanse las mediocres series de televisión El show de Súper Mario Bros (1989), Las aventuras de Sonic el erizo (1993) o la película Súper Mario Bros (1993). 
diferentes a las ya asentadas creaciones de Shigeru Miyamoto y Nintendo (Mario, Link, Peach, Zelda, etc.) de la década anterior, todas ellas de estilo dulce, lindo y entrañable (Cruz, 2016).

\section{La mascota de Sega: Sonic, el erizo}

Presentado como "el videojuego más rápido de la historia" (Pettus, 2013), Sonic, el erizo, fue un videojuego protagonizado por un erizo antropomórfico de color azul (el color corporativo de Sega) y vestido únicamente con botas rojas y unos guantes blancos. Este personaje fue planteado por Hayao Nakayama y creado por Yuji Naka gracias a los diseños de Naoto Ōshima (Pettus, 2013) para la nueva consola Mega Drive de Sega de 16 bits), una videoconsola que esta compañía creó para sustituir a su antecesora de 8 bits (denominada como Master System).

Este erizo es el protagonista de una franquicia completa de videojuegos y durante décadas fue el estandarte de la compañía desarrolladora de software y hardware Sega. Esta figura es la total contraposición de Mario: un animal joven, ágil, esbelto y veloz, caracterizado por tener una personalidad carismática, rebelde y chulesca. Orgulloso de sí mismo y siempre interesado en divertirse, este animal es de conducta valiente y de buen corazón e, igual que Mario, siempre desbarata los maléficos planes de su archienemigo.

De todas maneras, Sonic no fue el primer intento de Sega a la hora de crear una mascota corporativa, pues ya en la década de los 80 esta compañía japonesa buscó fortuna primero de la mano de Opa-Opa y posteriormente con Alex Kidd, pero el dominio absoluto de Nintendo en el sector de las videoconsolas, incluido los productos portátiles (Belli y López, 2008), hizo que estos personajes no tuvieran ninguna oportunidad en este competitivo mercado.

Debido a estos fracasos, Nakayama tenía claras las características fundamentales del nuevo representante de Sega. Tendría que ser fácil de reconocer y alejarse de los convencionalismos clásicos de otros elementos diseñados por la compañía (Pettus, 2013), un personaje nuevo e innovador para una videoconsola moderna.

El impacto de la nueva mascota y una agresiva campaña comercial ${ }^{5}$, fueron fundamentales para el éxito de la consola Mega Drive, llegando incluso a superar en ventas (en Estados Unidos) a la videoconsola de 16 bits Super Nintendo) y su juego estrella Super Mario World (Pettus, 2013), por ello se denomina popularmente a este período histórico de enorme rivalidad entre Nintendo y Sega como "la guerra de las videoconsolas". Este nivel de competitividad empresarial y el elevado grado en el que los consumidores se identificaban con una marca o con otra, jamás se volvería a producir ${ }^{6}$.

Fue célebre un anuncio televisivo de Sega en el que se alababan las virtudes de su videoconsola Mega Drive (o Génesis) en comparación con su rival de Nintendo a través de un juego de palabras: "Genesis does what Nintendo don't".

6 Aun así, gracias a la enorme fama de la propia Nintendo, Mario y otras franquicias exclusivas de la compañía, junto al impresionante surtido de juegos que esta empresa poseía, permitieron a la videoconsola NES mantenerse con vida hasta mediados de la década de los 90 y que su videoconsola sucesora tuviera magníficas ventas a nivel global. 
Retornando al personaje de Sega, de todas sus características, había una que sobresalía del resto: su velocidad (figura 1). Esta característica no fue escogida al azar, pues la rapidez del erizo azul permitió a Sega que la población pudiera asociar la tríada personaje-videojuego-videoconsola como un todo y comparar los avances tecnológicos de su consola de 16 bits, Mega Drive, frente a la aún vigente (y muy rentable) NES de 8 bits, siendo la rapidez un concepto más fácil de entender por la sociedad, que un simple aumento de bits entre diferentes videoconsolas.

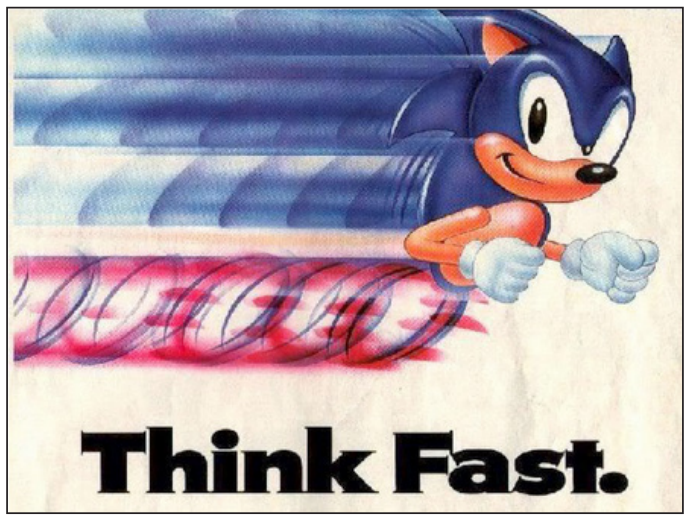

Figura 1. Anuncio de Sonic, el erizo (Pettus, 2013)

Fuente: imagen recuperada del sitio web Retroplayers,

http://www.retroplayers.com.br/retroespeciais/retrofast-23-anos-sonic-top-10-jogos-preferidos/8/

Si bien tras el éxito inicial de la nueva videoconsola Master System, las aventuras de Sonic se fueron enriqueciendo a través de nuevos videojuegos en los que se iba presentando un mundo con nuevos personajes y tramas más avanzadas. Los posteriores productos de Sega no alcanzaron el éxito comercial esperado (la saga Sonic incluida) y la compañía decidió, a inicios del siglo XXI, renunciar a seguir produciendo hardware, siendo la videoconsola de sobremesa Dreamcast, la última que esta compañía desarrollaría.

Esto no impidió que Sonic siguiera protagonizando videojuegos (con resultados ambivalentes), o incluso actuar en productos de forma conjunta con su eterno rival Mario, debido a que la popularidad de este personaje animado siguió manteniéndose intacta, pues para numerosas generaciones, Sonic sigue siendo la representación por antonomasia del mundo de los videojuegos, solo siendo superado su celebridad por Mario, el icónico personaje de Nintendo.

\section{La mascota de Sony: Crash Bandicoot}

Durante el período histórico en el que Nintendo y Sega copaban el sector de las videoconsolas con la Super Nintendo y la Mega Drive, apenas hubo intentos relevantes de terceras compañías en romper el duopolio existente de este competitivo mercado, teniendo que esperar las demás empresas hasta el final de la vida útil de las videoconsolas de 16 bits y la aparición de las nuevas generaciones de videoconsolas (de 32 y 64 bits). 
Una de estas entidades que decidió introducirse a este mercado fue Sony con su videoconsola PlayStation (de 32 bits), la cual fue lanzada a finales de 1994 con un gran éxito después de no prosperar un intento de colaboración con Nintendo. Se vendieron más de 100 millones de estas videoconsolas en diez años, y actualmente los productos de Sony cuentan con un prestigio elevado como empresa creadora de videojuegos.

Si Mario era la franquicia estrella de Nintendo y Sonic lo era de Sega, la mascota corporativa de Sony podría identificarse en Crash Bandicoot (figura 2), videojuego protagonizado por Crash, el personaje de la franquicia de juegos que lleva el mismo nombre, el cual fue creado en 1996 por la compañía estadounidense Naughty Dog (Martínez, 2016) en exclusiva (inicialmente) para la consola PlayStation. Crash es el protagonista de un juego de plataformas y, al igual que Sonic, es un animal antropomórfico, si bien se diferencia del erizo azul en que presenta una personalidad más de estilo grunge ${ }^{7}$, más ingenua y despistada que la mascota de Sega de tal forma que el humor logra, en esta saga de juegos, una mayor presencia que en las franquicias de Mario y Sonic.

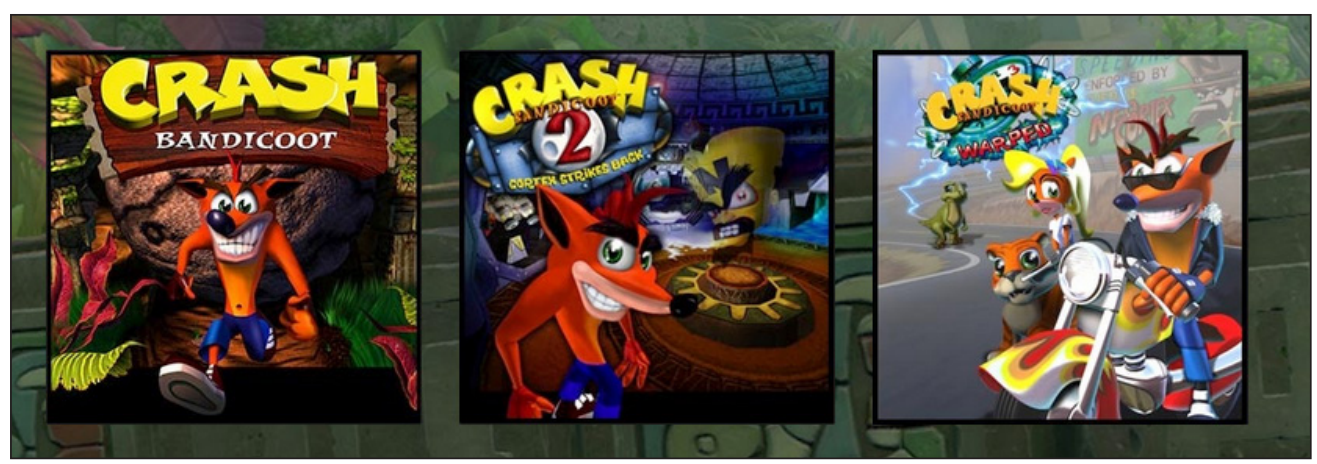

Figura 2. Carátulas de videojuegos de la saga Crash Bandicoot

Fuente: imagen recuperada de https://www.crashbandicoot.com/es

Vestido con un pantalón azul y unos zapatos deportivos de color rojo (al igual que Sonic), Crash es un animal modificado genéticamente que en su primer videojuego tiene que rescatar a su novia (parecido argumento al de los videojuegos de Mario) de las malvadas garras de un perverso científico, siendo las semejanzas con el juego de Super Nintendo, Donkey Kong, más que evidentes (Martínez, 2016).

El éxito de la consola de Sony catapultó a la fama a este personaje, si bien el mayor poder tecnológico de las siguientes generaciones de videoconsolas, a largo plazo, sería el peor enemigo de los juegos tradicionales de plataformas, pues este tipo de videojuegos eran favorecidos por la rigidez y sencillez de las dos dimensiones. Limitaciones que permitían desarrollar múltiples juegos de plataformas en las antiguas consolas de 8 y 16 bits, pero con el salto tecnológico a las tres dimensiones, muchas sagas de videojuegos de este género no supieron adaptarse a este nuevo entorno al que se dirigía el mercado de forma inexorable.

La influencia de grupos de música de esa época como Nirvana y su líder, Kurt Cobain es más que notable. 
Crash es el claro ejemplo del declive de estos personajes, pues tras hacerse con sus derechos diferentes compañías, sus videojuegos cada vez tenían peores ventas que los iniciales (Martínez, 2016) y la propia Sony (de manera no oficial) reemplazaría a este animal antropomórfico como su estrella por otro: Spyro, un dragón de color púrpura que tuvo una fama efímera.

\section{La mascota de Ubisoft: Rayman}

Creado en 1995 por Michel Ancel (Peña, 2015), Rayman es un personaje de una saga de videojuegos que hizo su primera aparición en un juego de plataformas de desplazamiento horizontal en dos dimensiones de mismo nombre que su protagonista: Rayman. Diseñado y publicado por la empresa francesa Ubisoft para diferentes videoconsolas, Rayman logró su mayor popularidad en la PlayStation de Sony, llegando a alcanzar 28 millones de copias vendidas durante toda su historia (Peña, 2015).

Rayman es una figura humanoide cuya característica física más notoria es que no posee ni extremidades ni cuello (figura 3) y, al igual que otras mascotas corporativas, viste con zapatos deportivos y guantes blancos, y su meta es restaurar la paz en su mundo y derrotar al tradicional malhechor prototípico de estos de productos.

El personaje de Ubisoft comparte con otros seres de videojuegos la capacidad de volar-planear y se diferencia de otros en que su existencia y propia personalidad no están tan bien definidas. Se puede afirmar que esta figura tiende a actuar de forma infantil, alegre e impulsiva y su personalidad es una mezcla de características dulces o kawaii (como los personajes de Nintendo) y cool (como los personajes de Sega).

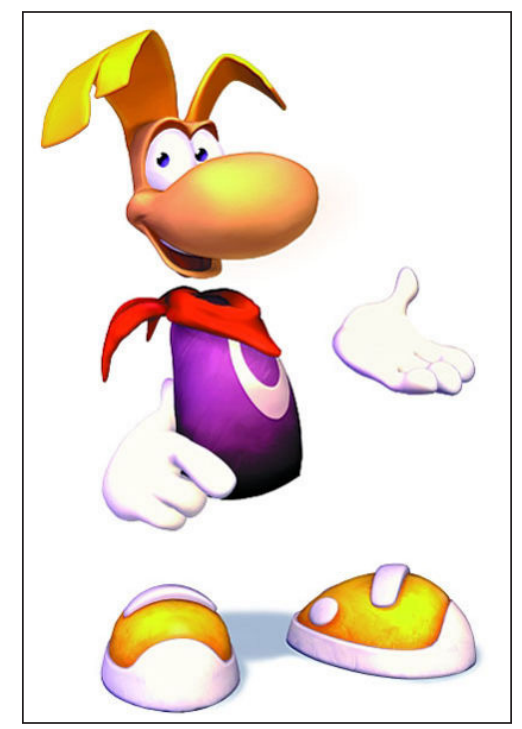

Figura 3. Rayman, el personaje de videojuegos de Ubisoft

Fuente: Imagen recuperada de Wikipedia, https://raymanpc.com/wiki/es/Rayman _ (serie) 
Posteriormente, en sus siguientes secuelas, Rayman cedió el protagonismo de sus juegos a personajes que surgieron inicialmente como unos nuevos villanos de la franquicia: los rabbids (conocidos en los mercados francófonos como les lapins cretins), unos conejos caracterizados por su comportamiento salvaje, estúpido y alocado que consiguieron una gran popularidad a inicios del siglo XXI, tras aparecer en el año 2006 en el videojuego Rayman: raving rabbids.

A diferencia de otras mascotas corporativas, el diseño de Rayman se caracterizaba por no seguir el patrón común de la época: la estética de los años 90, y puede ser que este factor explique la longevidad de este personaje en comparación con la corta vida de otras mascotas corporativas; aunque este renombre nunca alcanzaría el mismo nivel de las principales figuras de Nintendo o Sega.

\section{La mascota de Sunsoft: Aero, el murciélago}

Al igual que Ubisoft, Sunsoft (una división electrónica de la compañía japonesa Sun Electronics) nunca fue una empresa creadora de hardware de videojuegos, centrándose únicamente en la creación de videojuegos para otras compañías con un éxito aceptable durante la década de los años 80.

Con la creación en 1993 (por parte de Iguana Entertainment para Sunsoft) de un videojuego del clásico género de plataformas horizontales en dos dimensiones protagonizado por un murciélago acróbata: Aero, the acro-bat (figura 4), elaborado para las videoconsolas de sobremesa Super Nintendo, Mega Drive y para la portátil Game Boy Advance, Sunsoft vio en el nacimiento de este mamífero volador, la posibilidad de tener una mascota carismática que fuera el símbolo de la empresa, siguiendo la tendencia de la época.

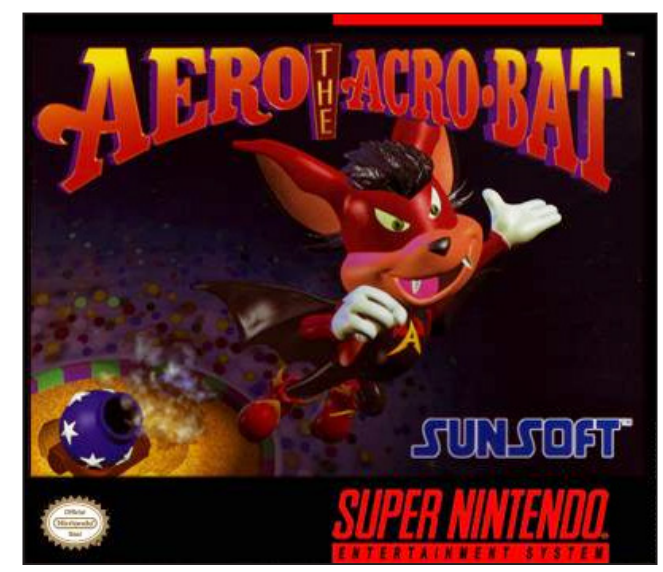

Figura 4. Portada del videojuego Aero the acro-bat para Super Nintendo

Fuente: Imagen recuperada de Mundo retrogaming,

http://retrogamming.blogspot.com/2015/06/aero-acro-bat-super-nintendo.html 
Aero es una de las numerosas mascotas "con personalidad" tan típicas de la década de los 90 que tuvo un éxito en ventas aceptable y críticas positivas, si bien poseía prácticamente todas las características físicas y psicológicas de Sonic y su meta era idéntica a la de Mario y Crash (rescatar a su novia del bellaco de turno), diferenciándose únicamente del resto en que su primer videojuego presentaba un contexto más determinado y cerrado que los entornos de Mario, Sonic, Crash o Rayman: el mundo del circo.

Debido a una expansión excesiva, Sunsoft, en 1995, decidió centrarse únicamente en el mercado japonés, si bien antes se crearon una secuela y un spin-off de esta saga, para finalmente vender los derechos de esta mascota-personaje a sus creadores originales no volviendo Aero a protagonizar ningún videojuego más.

\section{La mascota de Accolade: Bubsy, el gato montés}

Bubsy, es el ejemplo más exagerado de cuándo una empresa quiere tener el mismo éxito de Sega con Sonic. Creado en 1993 para las consolas Super Nintendo y Mega Drive, Bubsy, un gato montés de Norteamérica (figura 5) fue presentado al público y a los videojugadores como "el nuevo Sonic", se pueden definir sus habilidades físicas en el primer videojuego de plataformas que protagoniza (Bubsy in: Claws Encounters of the Furred Kind) como una mezcla de la velocidad y personalidad de Sonic y la jugabilidad de los productos de Mario.

Una característica básica de este personaje es el uso de constantes muletillas para lograr el tan ansiado aplauso de los amantes de los videojuegos (Griefas, 2010, p. 168), estrategia que ya, anteriormente, había aplicado con enorme éxito Bugs Bunny (el personaje de dibujos animados de los años 40) y su célebre frase "Eh... What's up, doc?".

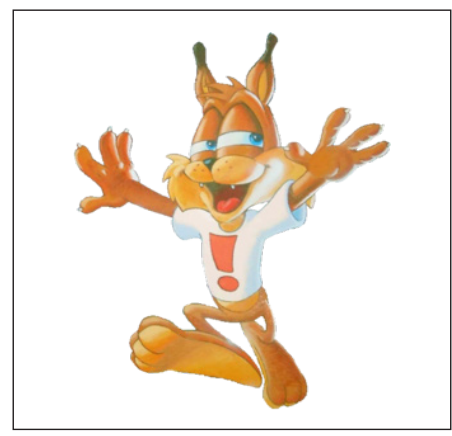

Figura 5. Bubsy, el personaje diseñado por Accolade

Fuente: Wikipedia. https://en.wikipedia.org/wiki/Bubsy

Al igual que los videojuegos protagonizados por la mascota de Sunsoft, Bubsy tuvo una aceptable acogida en sus primeros videojuegos a pesar del anodino y repetitivo argumento que gira alrededor de la trama que protagoniza este animal ${ }^{8}$, desarrollándose dos

8 El argumento del primer juego de Bubsy hace referencia al robo de todos los ovillos de lana del planeta por parte de unos extraterrestres, historia que tiene enormes similitudes con el argumento del primer videojuego de la Super Nintendo de Donkey Kong: Donkey Kong Country (1994). 
secuelas de plataformas bidimensionales y una tercera en un formato tridimensional, pues a diferencia de Aero, este felino sí logró realizar este paso evolutivo con la aparición de Bubsy 3D, un producto lanzado en 1996 para la consola PlayStation que en la actualidad es considerado como uno de los peores videojuegos de toda la historia debido a su nefasta jugabilidad y sus pésimos gráficos.

El fracaso en ventas de Bubsy 3D fue notorio y mortal para la compañía Accolade que terminó siendo comprada por Infogrames en el año 1999. Para más escarnio, Bubsy 3D había salido al mercado a la vez que el afamado Mario 64, el primer juego para la videoconsola de 64 bits de Nintendo, un arrollador triunfo de ventas y críticas especializadas que es considerado en la actualidad el juego pionero de plataformas tridimensionales.

\section{Gex el lagarto: la mascota de Crystal Dynamics}

Gex, es un videojuego de plataformas (inicialmente en dos dimensiones) creado en 1995 por la empresa Crystal Dynamics, cuyo personaje central es un gecko antropomórfico cuya prenda de vestir más característica son unas gafas de sol (figura 6). Gex sigue la tradición de las compañías de videojuegos de la época de tener como protagonista en alguno de sus juegos a un reptil, pues si Nintendo logró con Yoshi un nuevo personaje con tirón popular, las demás compañías propusieron con peor fortuna a otros personajes del mismo reino animal como Radical Rex (un videojuego sobre un tiranosaurio en monopatín publicado en 1994 por Activision y desarrollado por Beam Software) o Croc (un cocodrilo protagonista de videojuegos de plataformas de tres dimensiones publicado por Fox Interactive y desarrollado por Argonaut Software).

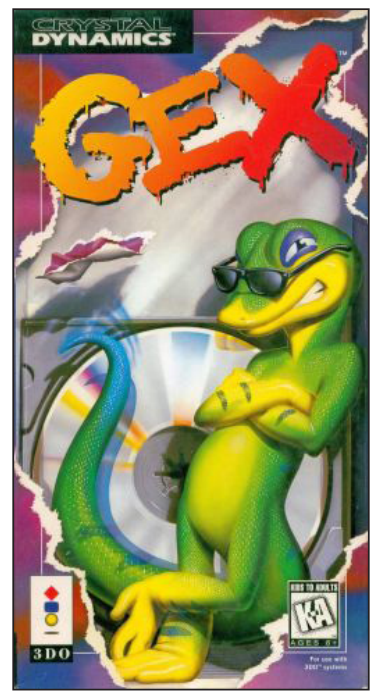

Figura 6. Gex: mascota de Crystal Dynamics

Fuente: Wikipedia. https://en.wikipedia.org/wiki/Gex_(video_game) 
Gex, a diferencia de las anteriores mascotas corporativas, es un producto de marketing más enfocado a los adolescentes, pues este animal comparte las aficiones de este colectivo. Gex es un adicto a los programas de televisión, la música y el surf, además de usar un lenguaje con claras connotaciones de índole sexual.

Con un juego y dos secuelas en su espalda, al igual que otras mascotas de videojuegos, Gex tuvo una aceptable acogida por parte del público de los años 90, si bien con el cambio de siglo, las tendencias clásicas de esta década ya no tuvieron la misma aceptación de años pasados y estos personajes fueron cayendo en el olvido.

Este fue el caso de Gex, pues el futuro de este descarado lagarto quedó truncado después de que la empresa Crystal Dynamics fuera comprada por Eidos Interactive en 1998, saliendo en 1999 su último juego: Gex 3: Deep Cover Gecko. Al igual que Bubsy, este reptil también dio el salto a los videojuegos de plataformas de tres dimensiones, pero obteniendo resultados de ventas mediocres.

\section{Titus el zorro: la mascota de Titus Interactive}

El ejemplo más evidente en el que una empresa de videojuegos quiso que se le asociara con un animal antropomórfico-mascota, fue Titus, un zorro que representaba a la empresa francesa distribuidora de videojuegos del mismo nombre (figura 7).

En 1991 la compañía francesa Titus Interactive creó el videojuego Lagaf: Les Aventures de Moktar, cuyo protagonista era el humorista y presentador de televisión francés Vicent Lagaf. El éxito de este producto en su país natal, llevó a la compañía a modificar el juego para el mercado internacional, al igual que hizo Nintendo con Super Mario 2, sustituyendo a este cómico por la propia mascota de la compañía y creando, un año después, el juego Titus the Fox: To Marrakech and Back, una simple y burda adaptación del anterior producto, que tuvo una mala acogida ante el público.

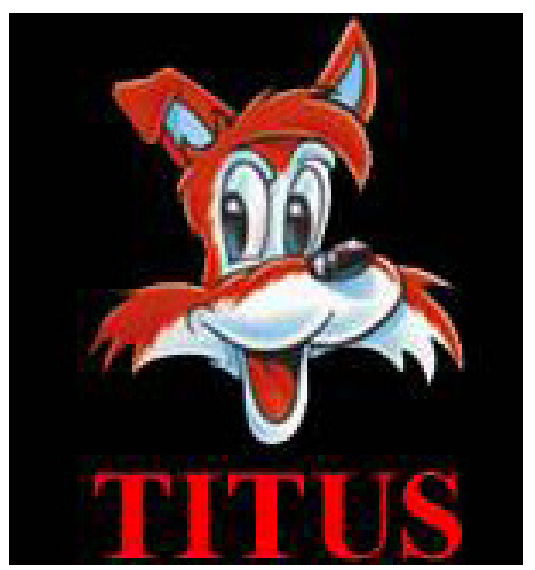

Figura 7. Logo empresarial de Titus Interactive

Fuente: Wikipedia. https://en.wikipedia.org/wiki/Titus _ Interactive 
Titus Interactive, al igual que Accolade, se haría tristemente célebre en el sector por crear uno de los peores videojuegos de tres dimensiones: Superman 64 (1999) para la Nintendo 64, desapareció esta compañía al declararse en bancarrota en el año 2005.

\section{Otras mascotas corporativas}

A mediados de los años 90, el mercado de los videojuegos ya estaba completamente colapsado con una infinidad de mascotas de videojuegos, e incluso, otros sectores como el alimenticio (refrescos y aperitivos) dieron el salto a esta industria (véase los paradigmáticos ejemplos de los videojuegos protagonizados por los personajes de Fido Dido y Chester Cheetah, iconos significativos de esta época histórica).

A pesar de que hubo intentos meritorios por crear personajes emblemáticos de gran calidad y originalidad como Earthworm Jim (una saga creada en 1994 por Shiny Entertainment), la mayoría de mascotas fueron fallidos intentos publicitarios para conseguir popularidad y reconocimiento rápido que fracasaron estrepitosamente. A modo de ejemplo, se pueden citar otros animales antropomórficos que protagonizaron más videojuegos:

- Zool (1992): un gremlin ninja alienígena que protagonizó dos juegos creados por la empresa Gremlin Interactive.

- Mr. Nutz (1993), una ardilla roja vestida con una visera y zapatos deportivos de la compañía Ocean.

- Sparskter (1994): una zarigüeya que ejercía de caballero medieval y que se consideraba la mascota de Konami.

- $\quad$ Blinx (2002): un gato que pretendía ser la mascota de la X6ox, la exitosa videoconsola de Microsoft.

- $\quad$ Ty (2002): el tigre de Tasmania de Krome Studios 9 .

\section{Conclusiones}

Ya sea por su sexo (todos los personajes analizados son protagonistas y de género masculino mientras que los personajes femeninos son meras acompañantes o recompensas finales), su psique (seres atrevidos, llenos de vitalidad, y rebeldía), su vestimenta (uso de ropa deportiva, gafas de sol...), sus aficiones (interés por la música ${ }^{10}$, la televisión, los deportes...) o su motivación para actuar y comportarse (rescate de personajes femeninos), los personajes de videojuegos de los años 90 se caracterizan, en general, por poseer unos

$9 \quad$ El siguiente enlace muestra un anuncio comercial del personaje de Ty (2002), evidencia de los claros objetivos de su compañía creadora: la eliminación directa de los otros personajes de la competencia. https://www.youtube.com/ watch?v=rxzhEJG7 _ $6 \mathrm{w}$

10 Existe una evidente relación entre la música de Michael Jackson y la banda sonora de Sonic 3, si bien el cantante no aparece en los créditos oficiales de tal videojuego. Respecto a la mascota de Sunsoft, Aero el murciélago, este en su primer videojuego, se presenta con gafas de sol y haciendo el célebre baile moonwalk de este popular cantante estadounidense. 
patrones comunes que se repiten de forma constante y que perfectamente se podrían encuadrar con las características de la generación Y: inmediatez, alto estatus social juvenil y una clara ruptura con los símbolos de las anteriores generaciones.

De la gran cantidad y número de mascotas noventeras, el personaje más popular de todas ellas fue Sonic cuyas características físicas y psicológicas fueron la pauta común que tendrían el resto de mascotas de empresas de videojuegos de este período. Sonic era el representante cool de la nueva consola de 16 bits de Sega (en contraposición a Mario y la NES, la videoconsola de 8 bits de Nintendo) que fue puesta a la venta a inicios de la década de los 90.

Si bien la necesidad de contar con una mascota digna de competir con Nintendo, el cual formaba un cuasi-monopolio global a finales de los años 80, hacía entendible y lógica la aparición en los años 90 de un personaje como Sonic, la aparición de nuevas empresas de hardware de videojuegos como Sony y Microsoft (emporios que finalmente romperían el rígido duopolio Nintendo-Sega de finales del siglo XX), produjo una rápida saturación de personajes de escasa originalidad, lo que, explicaría el rápido declive de la mayoría de mascotas corporativas de videojuegos.

El binomio sociedad-productos culturales van inequívocamente de la mano, y los videojuegos son una parte básica de la cultura y de los agentes de socialización, pues como afirma Garin (2009, p. 96):

El videojuego entronca con una corriente bien localizada de productos culturales masivos que, entre el cine, el cómic y la televisión han nutrido la cultura popular del pasado siglo, entendido al mismo tiempo como medio de consumo de masas y como reverberación de tal masificación en un universo compartido por millones de espectadores, lectores y jugadores.

A partir del nuevo milenio, las empresas de videojuegos fueron separando sus marcas comerciales de las antiguas mascotas corporativas y prefirieron centrarse en campañas de marketing y publicidad más enfocadas a los propios productos que se vendían (ya fueran videojuegos o videoconsolas), intentando asociar el nombre de la empresa con conceptos más abstractos como las ideas de fiabilidad, diversión, calidad o excelencia.

De todos modos, es digno mencionar que la crítica más certera que se ha realizado a esta invasión de estos personajes estereotipados, la haría en 1997 la serie animada Los Simpsons en el capítulo 167 de su octava temporada titulado The Itchy \& Scratchy \& Poochie Show, en el que la trama gira a la aparición de Poochie" ${ }^{11}$, un nuevo personaje que es creado ad hoc por una productora de dibujos animados para aumentar su escasa audiencia y conectar nuevamente con los jóvenes, esta susodicha animación es una parodia violenta de los clásicos personajes Tom y Jerry (Henry, 1994, p. 96).

No confundir con Poochy, perro que aparece por primera vez en el videojuego de Super Nintendo, Super Mario World 2: Yoshi 's island (1995). 
El nombre de Poochie se ha convertido en la categoría descriptiva de la mayoría de los personajes de videojuegos anteriormente citados, pues este cánido representaba fielmente la idea negativa de los personajes de videojuegos o de televisión, cuyo único objetivo era captar la atención del público ofreciéndose a la audiencia, de forma descarada, ilógica y tediosa.

Las mascotas corporativas de videojuegos presentaban las características más típicas de finales del siglo XX que se asocian con los primeros millennials: la rebeldía y el interés por la tecnología, y se puede definir a este tipo de personajes como chulescas figuras de escasa popularidad, introducidas meramente por objetivos comerciales, que demandaban permanentemente la atención del público en contraposición a los demás personajes.

A pesar de representar lo que en teoría la sociedad demandaba de un personaje de ficción, Los Simpsons recrearon fielmente en Poochie la equivocada toma unilateral de decisiones empresariales a la hora de crear un nuevo producto o de modificar uno ya existente, pues en el respectivo episodio, el nuevo personaje es recibido con críticas muy negativas debido a su falta de integración en el ambiente en el que se sitúa, la incoherencia de su historia argumental y lo forzado y poco natural de sus actuaciones.

En definitiva, Sonic y sus múltiples (y burdas) copias, simbolizaron una época de los videojuegos en los que esta industria quería representar la innovación y el éxito a través de simples y vulgares clichés marcados por un mismo patrón de personalidad y similar vestimenta. La sobreexplotación de estas figuras y los cambios en la sociedad hicieron que la vida de estas mascotas corporativas fuera, en la mayoría de las ocasiones, de efímera duración.

\section{Referencias}

Benito, J. (2012). El mercado del videojuego: unas cifras. Icono 14, 4(1), 36-47. doi.org/10.7195/ri14. v4i1.396

Belli, S. y López, C. (2008). Breve historia de los videojuegos. Athenea Digital, 14, 159-179. doi. org/10.5565/rev/athenead/v0n14.570

Cataldi, Z. y Dominighini, C. (2015). La generación millennial y la educación superior. Los retos de un nuevo paradigma. Revista de Informática Educativa y Medios Audiovisuales, 12(19), 14-21.

Cruz, R. (2016). Análisis de la obra de Miyamoto a través de sus personajes y la influencia en Occidente tras la primera crisis del videojuego. En A. Gómez-Aragón (Ed.), Japón y Occidente. El Patrimonio Cultural como punto de encuentro (pp. 763-772). Sevilla: Aconcagua.

De Diego, R. (2013). Bowser Lives. Pautas para el diseño de villanos con valor pedagógico. Revista LifePlay, (1), 69-84.

Del Olmo, D. (2013). Acercamiento al aprendizaje conductual bajo el mundo 1-1 de Súper Mario Bros. Revista LifePlay, (1), 85-100.

Esposito N. (2005). A short and simple definition of what videogames is. Compiègne: University of Technology of Compiègn. 
Feixa, C. (2006). Generación XX. Teorías sobre la juventud en la era contemporánea. Revista Latinoamericana de Ciencias Sociales, Niñez y Juventud, 4(2).

Garfias, J. (2010). La industria del videojuego a través de las consolas. Revista Mexicana de Ciencias Políticas y Sociales, 52(209), 161-179.

Garin, M. (2009). Mitojuegos. Sobre el héroe y el mito en el imaginario Nintendo. Comunicación, 7(1), 94- 115 .

Henry, M. (1994). The Triumph of Popular Culture: Situation Comedy, Postmodernism and "The Simpsons". Studies in Popular Culture, 17(1), 85-99.

Kraak, V.I y Story, M. (2014). Influence of food companies' brand mascots and entertainment companies' cartoon media characters on children's diet and health: a systematic review and research needs. Obesity Reviews, 16(2), 107-126. doi.org/10.1111/obr.12237

Lafrance, J.P. (2003). El juego interactivo: el primer medio de masas de la era electrónica. Quaderns del CAC, (15), 59-68.

Mangirón, C. (2012). Manga, anime y videojuegos japoneses: análisis de los principales factores de su éxito global. Puertas a la lectura, (24), 28-43.

Martínez, D. (2016). Crash Bandicoot: 10 claves para conocer a la mascota de Sony. Recuperado de http://www. hobbyconsolas.com/reportajes/crash-bandicoot-10-claves-conocer-mascota-sony-75536

Nintendo. (s.f.). La historia de Nintendo. Recuperado de https://www.nintendo.es/Empresa/La-historia-deNintendo/La-historia-de-Nintendo-625945.html

Peña, A. (2015). 20 años con Rayman, la mascota de Ubisoft. Okdiario.com. Recuperado de https://okdiario. com/videojuegos/2015/1 1/17/rayman-20-aniversario-rayman-adventures-7459

Pereira, F. y Alonzo, T. (2017). Hacia una conceptualización de los videojuegos como discursos multimodales electrónicos. Anagramas Rumbos y Sentidos de la Comunicación, 15(30), 51-64. doi. org/10.22395/angr.v15n30a2

Pérez, Á. (2014). El aprendizaje con videojuegos. Experiencias y buenas prácticas realizadas en las aulas españolas. Escuela Abierta, 17, 135-156.

Pettus, S. (2013). Service Games: The Rise and Fall of SEGA. Charleston: CreateSpace Independent Publishing Platform.

Ramos, D. y Ortega, F. (2017). La revolución en los hábitos de uso y consumo de vídeo en teléfonos inteligentes entre usuarios millenials: la encrucijada revelada. Revista Latina de Comunicación Social, 72, 704-718.

Rivera, E. y Torres, V. (2018). Videojuegos y habilidades del pensamiento. Revista Iberoamericana para la Investigación y el Desarrollo Educativo, 8(16).

Rochford, L. (2016). Contrepoint - Millenials, Y, Z. Et après? Informations Sociales, 195, 6.

Rosario, R. (2001). El cannon cool: joven literatura anglo-americana de los 90. Anales de la Universidad Metropolitana, 1(2), 111-116. 
Ruiz, J. (2017). Millennials y redes sociales: estrategias para una comunicación de marca efectiva. Miguel Hernández Communication Journal, 8, 347- 367.

Squire, K. y Steinkuehler, C. (2005). Meet the gamers. Library Journal, 130(7), 38-41.

Vargas, L. (2014). Videjugando: focalización atencional y rememoración en preadolescentes ¿Pueden atender procesos simultáneos y dejar espacio a la publicidad? Anagramas Rumbos y Sentidos de la Comunicación, 12(24), 21-38.

Vázquez, P. (2016). Revisión de un artículo reciente de Díez-Gutiérrez (2014) y revisión cualitativa de los videojuegos analizados en Díez-Gutiérrez et al. (2004). Cuestiones de Género: de la Igualdad y la Diferencia, (1 1), 509-522. http://doi.org/10.18002/cg.v0i1 1.3576 